\title{
Psychiatry recruited you, but will it retain you? Survey of trainees' opinions
}

\author{
Christina Barras, $^{1 \star}$ Jessica Harris ${ }^{2 \star}$
}

The Psychiatrist (2012), 36, 71-77, doi: 10.1192/pb.bp.111.034413

${ }^{1}$ South London and Maudsley NHS Foundation Trust, London, UK; ${ }^{2}$ South West London and St George's Mental Health NHS Trust, London, UK

Correspondence to Christina Barras (christinabarras@doctors.org.uk)

First received 2 Dec 2010, final revision 27 Sep 2011, accepted 5 Oct 2011
Aims and method To gather opinion from trainees across England about their current experiences and future career plans. This was done via an internet-based survey.

Results Out of the 359 responses we received, $65.8 \%$ of trainees planned to stay in psychiatry until retirement. Trainees felt several issues were problematic, including the attitude of other specialties towards psychiatry, perceived substandard treatment of psychiatric patients by other specialties and implications of New Ways of Working.

Clinical implications Despite there being many areas of training respondents were happy with, if attrition is to be minimised, issues such as how psychiatric trainees integrate with the other medical specialties and how the role of doctors in the specialty is perceived need to be addressed.

Declaration of interest None.
Retention in psychiatry has been a problem for a long time. Concern was initially raised that there were not enough British trainees to fill the gaps left by those who retired from the profession. ${ }^{1}$ Although the vacancy rate for psychiatrists has reduced, at $4.6 \%$ in 2010 it continues to be above that in many other specialties: $3.5 \%$ for all specialties, $3.6 \%$ in general medicine, $2.2 \%$ in obstetrics and gynaecology, and $9.1 \%$ in accident and emergency. ${ }^{2}$ Over the past 15 years there have been many papers published exploring the reasons for the deficit and with the aim of improving recruitment. Some of this work suggested methods of improving retention by changing recruitment, ${ }^{1,3}$ but less has been written about the problems faced by those in specialty training and the subsequent effect on retention.

Despite a consistent percentage of UK graduates expressing an early interest in psychiatry, $20-30 \%$ of these have been found to not be working in it 10 years post graduation. ${ }^{4}$ Several studies have tried to identify why trainees abandon psychiatry as their career choice. ${ }^{3,5-7}$ There were consistent themes within their results: poor public image and lack of respect from other specialties, work stresses and training difficulties. ${ }^{8}$ In January 2004, an action plan was adopted jointly by the Department of Health in England and the Royal College of Psychiatrists, to address long-standing problems with recruitment and retention facing the profession. ${ }^{9}$

Trainees' experiences are monitored through various means, including via Modernising Medical Careers and an annual survey by the Postgraduate Medical Education and Training Board (PMETB). Having completed this feedback, we felt that there was more to say about our experiences.

*The authors contributed equally to this work.
This study was designed to assess current difficulties trainees may be encountering and how these may affect their career paths.

\section{Method}

A survey was constructed using the Survey Monkey website (www.surveymonkey.com). It was piloted to a small group of trainees in South West London and St George's Mental Health NHS Trust and some modifications were made. The 14 English deaneries were contacted and asked to distribute an invitation email to their trainees. The survey opened in September 2009 and closed 3 weeks after the final response in early 2010.

Trainees were asked to provide basic information about themselves and their training. They were then asked to rate how problematic certain issues were for them on a scale of $0-10$, where $0=$ 'this has never been a problem' and $10=$ 'this is constantly a problem'. For each statement they were also asked whether this problem had ever made them consider leaving psychiatry. The issues were expressed in statements, for example 'I have not been well supervised', and came under the headings of 'training', 'working' and 'attitudes'. We included a non-applicable (N/A) option for each statement as in some cases trainees might not feel able to comment (e.g. core trainee year 1 (CT1) doctors would not be able to comment on the annual review of competence progression (ARCP) process as they have not been through it yet).

Respondents were also asked about their future career plans, including how long they planned to stay in the specialty. To finish, comment was invited under the question, 'Finally, what would you do to improve 
the retention to our specialty? Is it just about solving the above problems? Please let us know any ideas you have'. (The questionnaire is available from the authors on request.)

To analyse the results we calculated the median score and interquartile range (IQR) for each statement. We could not include the N/A responses but have specified how many of these there were for each statement and in most cases there were low numbers. For the qualitative data we grouped the responses into 13 broad categories. We then calculated the number of discrete comments in each category and selected three examples for each.

\section{Results}

\section{Demographics}

The survey yielded 359 responses from trainees. We estimated the number of core and higher trainees in the 14 deaneries in 2009 based on responses to the PMETB survey. ${ }^{10}$ This revealed a response rate of $16.1 \%$ (based on an estimated 2231 trainees). The majority of respondents (77.2\%) were CT/specialist trainee years 1-3 (ST1-3): CT1 $18.4 \%$, CT2 $27.3 \%$, CT3 $31.5 \%$. The rest were mainly higher trainees (ST4 6.7\%, ST5 7.0\%, ST6 5.6\%) and the remaining $3.6 \%$ were 'other' - senior house officers or registrars. In terms of age, the respondents were mainly between 26 and 35 years old (78.5\%). There was an equal gender distribution, with $47.8 \%$ female and $52.2 \%$ male respondents.

\section{Deaneries}

Four deaneries did not distribute the email to their trainees: Defence, East Midlands, Oxford and West Midlands. The majority of responses came from the London Deanery (46.8\%). Table 1 shows the percentage of responses by deanery.

\begin{tabular}{|lc|}
\hline Table 1 Percentage responses by deanery & \\
\hline Deanery & Response, \% \\
\hline Defence Postgraduate Medical Deanery & - \\
\hline East Midlands Healthcare Workforce Deanery & - \\
\hline East of England Multi Professional Deanery & 8.7 \\
\hline Kent, Surrey and Sussex Deanery & 4.5 \\
\hline London Deanery & 46.8 \\
\hline Mersey Deanery & 7.0 \\
\hline Northern Deanery & 12.3 \\
\hline North Western Deanery & 12.6 \\
\hline Oxford Deanery & - \\
\hline Severn Deanery & 0.3 \\
\hline South West Peninsula Deanery & 3.1 \\
\hline Wessex Deanery & 4.2 \\
\hline NHS West Midlands Workforce Deanery & - \\
\hline Yorkshire and the Humber Postgraduate Deanery & 0.6 \\
\hline
\end{tabular}

NHS, National Health Service.

\section{Intention to stay in UK psychiatry}

The majority of respondents (65.8\%) plan to stay in psychiatry until retirement. However, if people were to leave psychiatry the top three alternatives were: 'leave the UK and continue in psychiatry' (31.2\%), 'leave medicine for another type of work' (22.9\%) or 'retrain as a GP' (19.8\%). We broke this down further to see what effect training outside the UK, deanery and grade had on intention to stay in psychiatry and the top three alternatives people would consider if they left. Over half the respondents (54.1\%) obtained their medical degree outside the UK. Comparing UK and non-UK graduates there did not seem to be any difference in the intentions to stay in psychiatry until retirement $(64.0 \%$ and $68.1 \%$ respectively). There was, however, some variation in what respondents would do if they left. Non-UK graduates were most likely to 'leave the UK and continue in psychiatry' (33.9\%), 'pursue a career in research' $(21.2 \%)$ or 'retrain as a GP' (17.5\%), whereas UK graduates would 'leave medicine for another type of work' (39.9\%), 'leave the UK and continue in psychiatry' (27.8\%) or 'retrain as a GP' $(22.8 \%)$.

Looking at stage of training, higher trainees were slightly more likely to plan to stay in psychiatry until retirement than were core trainees $(76.5 \% v .63 .1 \%)$. If they left UK psychiatry, higher trainees would be most likely to: 'leave the UK and continue in psychiatry' (35.8\%), 'leave medicine for another type of work' (22.4\%), 'pursue a career in research' (16.4\%) or 'be caring for my family' (16.4\%). Core trainees would also be most likely to 'leave the UK and continue in psychiatry' (31.2\%), followed by 'retrain as a GP' (21.9\%) and 'leave medicine for another type of work' (21.6\%).

Comparing deaneries, more respondents from outside London plan to stay in psychiatry until retirement than those in the London Deanery (71.7\% v. 59.0\%). If they left, respondents from outside London would plan to 'leave the UK and continue in psychiatry' (31.7\%), 'leave medicine for another type of work' (23.5\%) or 'retrain as a GP' (19.7\%). Respondents from the London Deanery would 'leave the UK and continue in psychiatry' (30.9\%), 'leave medicine for another type of work' (22.4\%) or 'retrain as a GP' (20.0\%). We chose not to break down the results from other deaneries as many of the numbers were very small.

\section{Problems trainees may have encountered so far in their career in psychiatry}

Statements were all rated on a scale of 0-10. Tables 2, 3 and 4 show the median scores and IQR for each statement. Also included is the percentage of respondents who have considered leaving psychiatry because of that problem and the percentage who chose the N/A option.

\section{Qualitative responses}

Of the 359 trainees who completed the survey, 196 shared their ideas on how to improve retention in psychiatry. Many trainees made more than one comment and so in total 398 discrete comments were made. We grouped them into 13 broad categories. Table 5 lists the categories and number of 
Table 2 Statements related to training

\begin{tabular}{|c|c|c|c|}
\hline & \multirow[b]{2}{*}{ Median score (IQR) } & \multicolumn{2}{|r|}{$\%$} \\
\hline & & $\mathrm{N} / \mathrm{A}$ & Considered leaving \\
\hline I found the ARCP process unsatisfactory & $5(2-8)$ & 14.6 & 5.4 \\
\hline I do not think that the examinations reflect ability & $5(2-8)$ & 13.2 & 3.9 \\
\hline I had not enough time for audits/research & $5(2-7)$ & 1.1 & 0.8 \\
\hline I had poor-quality teaching & $3(1-5)$ & 0.8 & 2.5 \\
\hline I have not been well supervised & $3(1-5)$ & 0.8 & 2.2 \\
\hline I found the required assessments too time consuming & $4(2-7)$ & 3.4 & 2.2 \\
\hline
\end{tabular}

$A R C P$, annual review of competence progression; N/A, not applicable.

Table 3 Statements related to working

$\%$

\begin{tabular}{|c|c|c|c|}
\hline I spend too much time on paperwork & $7(5-8)$ & 0.8 & 4.8 \\
\hline I think that there is a lack of in-patient beds & $7(3-9)$ & 3.7 & 2.8 \\
\hline I find that clinical priorities take second place to meeting managerial objectives & $6(3-8)$ & 0.8 & 6.4 \\
\hline I think that medical problems are badly managed on the ward & $6(3-8)$ & 1.4 & 2.5 \\
\hline I think there is too much reliance on locum/agency staff & $5(2-7)$ & 3.7 & 1.4 \\
\hline I find that nursing staff are unmotivated & $5(2-7)$ & 1.1 & 1.4 \\
\hline I find my work stressful & $4(2-7)$ & 0.8 & 5.4 \\
\hline I do not have enough time to see my patients & $4(2-7)$ & 0.8 & 3.7 \\
\hline I find that I have problems with rotas & $3(1-7)$ & 2.0 & 2.5 \\
\hline I find that I have problems booking study leave & $3(1-7)$ & 4.2 & 1.7 \\
\hline I find myself in dangerous situations & $2(1-5)$ & 0.8 & 3.1 \\
\hline I am uncomfortable depriving patients of their liberty and enforcing treatment & $2(1-4)$ & 1.4 & 2.3 \\
\hline I find that I have problems booking annual leave & $2(1-5)$ & 1.4 & 0.8 \\
\hline I find the MHA difficult to work with logistically & $2(1-4)$ & 1.7 & 0.8 \\
\hline I have witnessed mistreatment of patients & $1(0-6)$ & 1.7 & 1.7 \\
\hline
\end{tabular}

MHA, Mental Health Act.

Table 4 Statements relating to attitudes

\begin{tabular}{|c|c|c|c|}
\hline & \multirow[b]{2}{*}{ Median score (IQR) } & \multicolumn{2}{|r|}{$\%$} \\
\hline & & $\mathrm{N} / \mathrm{A}$ & Considered leaving \\
\hline I think psychiatric patients get substandard treatment from other medical specialties & $8(5-9)$ & 2.0 & 2.0 \\
\hline I think there is a poor attitude towards psychiatry from other specialties & $7(6-10)$ & 2.2 & 2.2 \\
\hline I feel the future role of psychiatrists is being eroded by New Ways of Working & $7(3-9)$ & 5.0 & 8.4 \\
\hline I do not think that morale is high among medical staff & $6(3-8)$ & 1.7 & 3.7 \\
\hline I think the public's expectations of psychiatry are often too high & $6(3-8)$ & 2.3 & 1.1 \\
\hline I think that psychiatry is too poorly funded to be effective & $5(2-8)$ & 2.5 & 2.8 \\
\hline I don't think that I am paid enough for what I do & $4(1-8)$ & 1.4 & 3.1 \\
\hline I find some of my patients frustrating to deal with & $4(2-6)$ & 1.1 & 2.5 \\
\hline I think there are many poor-quality doctors in psychiatry & $4(2-7)$ & 1.7 & 2.0 \\
\hline I often feel demoralised & $3(1-5)$ & 0.8 & 3.9 \\
\hline I think psychiatry only seems to offer a 'revolving door' to patients & $3(1-6)$ & 0.8 & 2.3 \\
\hline I sometimes wish I was working in a different specialty & $2(0-6)$ & 1.1 & 5.0 \\
\hline I rarely have a sense of achievement & $2(1-5)$ & 1.4 & 2.8 \\
\hline I don't think psychiatry is evidence-based enough & $2(1-5)$ & 1.7 & 0.3 \\
\hline
\end{tabular}




\begin{tabular}{lc} 
Table $\mathbf{5}$ & Trainees' comments grouped into 13 categories \\
Category & $\%$ \\
\hline Attitudes towards psychiatry & 12.6 \\
\hline Professional role & 12.0 \\
\hline Day-to-day working & 11.3 \\
\hline Opportunities in training & 9.3 \\
\hline Patient care & 9.3 \\
\hline Assessments & 8.0 \\
\hline Recruitment & 8.0 \\
\hline Working with others & 6.3 \\
\hline Teaching and supervision & 6.0 \\
\hline Support systems & 6.0 \\
\hline Salary & 5.3 \\
\hline Morale & 5.3 \\
\hline Other & 1.3 \\
\hline
\end{tabular}

comments made. For each category we have given three examples of the comments received.

\section{Attitude towards psychiatry}

There were 50 comments related to this category and covered: educating doctors in other specialties about psychiatry, closer integration of psychiatry with other specialties, informing the public about what psychiatrists do and improving attitudes towards people with mental health problems.

'Educate other specialties that psychiatric doctors are as good as them, highlighting the cases they miss in A\&E and refer inappropriately, which may change their attitude towards us. Maybe they should shadow us as FYls during on calls to see we are as busy as they are.'

'4 weeks ago I was an F2 [foundation trainee year 2] in anaesthetics in a [district general hospital]. When I was working with consultants in hospital many of them were almost horrified that I had actually chosen to be a psychiatrist. I dealt with remarks such as "That's odd, you seem like such a well-balanced girl", and "Did you not get into anything else?". Four individual consultants told me "You're wasting yourself". By the time I actually started as a CT1 it was clear that psychiatry is very much viewed as second rate by other doctors, and I felt a bit demoralised, wondering if I had actually made the right decision after all.'

'I have noticed difficulty in referring acutely unwell patients to medics when I say I am an SHO [senior house officer] in psychiatry, as they almost expect the referral to be substandard.

\section{Professional role}

The vast majority of comments in this category related to a sense of eroded professionalism, with repeated suggestions to reverse the changes brought by New Ways of Working. ${ }^{11}$ Four trainees expressed their dislike of 'defensive practice'.

'Stop eroding my professionalism! I trained for many years to get to the relatively junior position I am in now. I am not replaceable by a nurse/social worker/[occupational therapist] who has done a short course on taking a history.'

'Stop allowing other mental health professionals and senior management to devalue us. I constantly feel that they do not see the point of us and keep us around to sign the paperwork and accept the risks they are unwilling to. Scrap New Ways of Working.'

'New Ways of Working - why bother to do [the] MRCPsych if your training (longer and more intellectually demanding than other allied healthcare professionals) counts for the same as allied roles with much briefer and limed training regimes? I think there should be great concern that we are being given training that in the end might not account for much in the real world of NHS acute service provision in terms of pay, role and influence.'

\section{Day-to-day working}

This category included comments about problems with rotas, not having enough time to spend with patients, lack of secretarial support and safety at work. Over $50 \%$ of the comments in this category were on the topic of paperwork.

'I often feel undervalued in ward rounds as my sole role is as a typist. I don't get time to see patients owing to IT-led reams of documentation ... I am my own secretary.'

'There are so many other commitments (compulsory teaching, [electroconvulsive therapy], psychotherapy, etc.) that there is little time left for clinical commitments, which is exacerbated by cross-covering other wards.'

'There is so much paperwork that people work mechanically and there is actually no sign of warmth in the service we provide.'

\section{Opportunities in training}

There was a wide variety of comments regarding opportunities in training and how these could be improved. Suggestions included an increased variety of jobs, improving opportunity to do research, greater trainee involvement in job planning and an increase in medical aspects of training.

'I think that combining the rotational training with neurology, geriatrics, GP and other medical specialties will improve the retention rates, making us believe that psychiatry is still evolving.'

'Improve allocation of rotations based on a preference and success ... I have been placed in jobs only doing general and old age [psychiatry] for 3 years. This is what would force me to leave the specialty as I am annoyed at being treated as a commodity.'

'More training flexibility with greater variation in the training experiences offered.'

\section{Patient care}

Trainees felt improvements were needed in many aspects of patient care, including medical care for psychiatric patients, quality of patient records, and resources available to patients in both in-patient and out-patient settings.

'I think the key issue is resources. My partner is an oncologist, and when we compare what there is to offer our patients, who often have similar levels of morbidity, the difference is staggering.'

'I think a culture of "need to be seen to be doing things correctly" is undermining the real patient care.'

'Lack of structured activity for ward patients, lack of availability of psychological and counselling services.'

\section{Assessment}

The category of assessment was roughly divided between comments expressing frustrations with the postgraduate 
exams, the ARCP process and workplace-based assessments (WPBAs)

'The exams are frustrating, have minimal clinical significance and are too subjective ... Psychiatry is losing a lot of good doctors as a result of these exams.'

'The paperwork requirements (WBA, ARCP, appraisal, CPD, etc.) are getting too much, with a lot of duplication. That can overburden trainees (and trainers), with the risk of emphasis being shifted from acquiring proper clinical skills to boxticking exercises.'

'WPBAs are time consuming and the system can be easily abused by those who wish to do so ... you do not have to learn from them to get through, just "get signed off". I am not sure they have validity as a test of competence.'

\section{Recruitment}

There were several themes in this category, including increasing and improving exposure of medical students to psychiatry and improving the 'quality' of doctors recruited.

'Raise the profile of psychiatry among medical students . . . Unfortunately I know of many trainees who came into psychiatry because it is "easy" and "non-competitive", with no real ambition to be psychiatrists.'

'It's about inspiring British-trained medical students with . . . enthusiastic consultants who allow medical students to see how fascinating the mind and its disorders are.'

'I find psychiatry is too much of a "last resort" option for trainees - it is extremely frustrating that I'm training with people who are doing psychiatry simply because they didn't get into any other specialty and as such [psychiatry] tends to be a dumping ground for poorly competent doctors. This of course then [has an impact] on the reputation of the specialty as a whole which deters people with an interest from entering it.'

\section{Working with others}

Comments in this category revolved around interacting with managers, other members of the multidisciplinary team and fellow doctors.

'The pressure from hospital managers is too much and they tend to be pushing us to the wall. They are also too quick to point fingers at doctors when problems arise and they have apparently made the practice of psychiatry very defensive. [General practice] will always be a better option to escape from hospital managers.'

'I get frustrated most by the reliance of HR [human resources] on locums for all types of staff - I may end up doing extra work because they can't, or don't have computer access, etc.'

'Improve the pay and teaching for HCAs [healthcare assistants], and let them know how valuable they are.'

\section{Teaching and supervision}

Some trainees felt that more formal teaching with their consultant was needed, aside from regular supervision. However, several trainees commented that teaching and supervision are areas where psychiatry is stronger than other specialties.

'All academic meetings are led by trainees where presentations are supervised. It would be better if there was more teaching led by consultants who share their expertise in diagnosis and treatment.'

'Better standard of teaching once in the profession, and encouragement to be professional and maintain knowledge and skills.'

'Part-time consultants should not be educational supervisors.'

\section{Support systems}

In this category, trainees suggested that improvements in career advice, attitudes to personal difficulties, help with managing stresses at work and greater senior support for their problems were key to improving retention.

'I am currently working with two doctors, one of whom is off sick with stress and the other is on the verge of a similar situation. There is no support for them and no clear lines to follow if the local structures aren't helpful. I'm only 2 months into CTl and am very disillusioned!'

'I think there needs to be greater focus in training, and during subsequent career, on how very taxing and emotionally challenging it is to work with people who are often in a very emotionally distressed state of mind. In doing so we are the direct recipients of all sorts of anxious, destructive/aggressive projections from our patients. We cannot manage these alone.'

'The main problem with my job at present is [that] I feel very poorly supported, often only being able to get in touch with supervising consultants sporadically. There are no registrars. I feel this is stressful and demoralising, and potentially dangerous.'

\section{Salaries}

On the issue of salaries, trainees called for pay scales relative to other careers and complained about unfair remuneration for hours worked and not being compensated for the risks they are exposed to.

'I think proper pay protection/not changing banding during training posts will help as this can be demoralising for doctors. Contracts should be for the whole training programme, not each post.'

'Better pay! I work part-time due to health reasons - my patients on benefits are paid more than me. This is very demoralising.'

'I would ensure that trainees do not suffer a continuous reduction of their income throughout training due to a dependency on on-call supplements.'

Morale

Trainees commented on low morale in the workforce, feeling that improving this would help boost retention.

'Demoralised consultants [have an] impact on junior staff morale. It really makes a difference when [one is] taught/ supervised by a motivated enthusiastic senior.'

'Poor morale in senior staff, especially staff grades - some have tried to persuade me to leave already.'

'Boost morale ... a among nursing staff. This has an inevitable positive effect on patients and generally makes working life less stressful.

Other

There were an additional five comments (two that were not suitable) that we could not fit into a specific category:

'The success rate of curing patients is too low.'

'Sorry, I think it is too late. I'm voting with my feet - once I have got my [Certificate of the Completion of Training] I'm of overseas before UK psychiatry loses its international credibility.'

'The question asked is what would I do to improve retention? The answer is simple, I will try to work hard, keeping an eye on the changing patterns of working and try to find my place with a realistic approach. 


\section{Limitations}

Trainees who are unhappy with training and consider leaving may have been more likely to complete a survey about retention. This may give a more negative picture than is actually the case. In addition, the statements trainees were asked to comment on were framed in a negative way, for example 'I spend too much time on paperwork'. Negative statements may have predisposed people to pessimistic thinking when they filled in the survey.

The majority of responses came from the London Deanery and therefore the views of trainees from other schemes have a much less of an effect on the results. The response rate of $16.1 \%$ was reasonable for a survey of this kind, however, generalisability may be limited as the majority of trainees did not complete the survey.

\section{Discussion}

Only $65.8 \%$ of respondents intend to stay in psychiatry until retirement. It is significant that the most popular alternative would be to continue working in psychiatry, but not in the UK. This suggests that it could be that the specialty itself is not the problem but rather it is the way mental health services operate in the UK which is leading trainees to practise elsewhere. It is interesting that training outside the UK did not seem to affect how long people plan to stay in UK psychiatry.

The survey revealed areas many trainees did not seem to consider problematic, for example supervision and teaching. Among other things, supervision was one of the areas targeted for improvement by the 2004 action plan. ${ }^{9}$ Therefore these results may be evidence of progress already made.

One issue that appears to cause problems is the amount of paperwork. Clearly, this is time consuming and is a problem that likely extends to other specialties. It is difficult to see how this can be improved. An increase in the number of administrative staff may be helpful, but this is unlikely to occur. Perhaps technology-based solutions such as dictation software could be considered. A perceived lack of in-patient beds also appears to be problematic. Unfortunately, given the current economic situation, this is something that is unlikely to improve, at least in the near future.

There does not appear to be any one problem that in itself would cause trainees to leave psychiatry. However, the highest number of respondents (8.4\%) had thought about leaving because they felt the future role of psychiatrists was being eroded by New Ways of Working. Generally, the main theme in terms of dissatisfaction was respect, not only respect from medical colleagues for psychiatrists and psychiatric patients, but also respect for the psychiatrist's role, even within the mental health profession itself. Our qualitative data echoed this, with most comments relating to attitudes towards psychiatry and the professional role.

The National Institute for Mental Health in England (NIMHE) National Workforce Programme (NWP) finished its work on New Ways of Working in March 2009, after 6 years. The NIMHE NWP aimed to improve workforce design and enable new ways of working across the different professions in psychiatry. Vize stated that the biggest single worry of those who have concerns about NWW [New Ways of Working]' is the effect on the role of the psychiatrist. ${ }^{11}$ The concern is that losing the traditional consultant's role 'will result in a future role that is ill defined and therefore less attractive, and which can more easily be substituted by other professions'. ${ }^{11}$ It continues to be essential, both for recruitment and retention, that the role of the consultant psychiatrist is clearly defined and valued, by both the mental health profession and the wider medical community.

It is difficult to get an accurate picture of the retention situation in other countries to compare with our findings in England. Similarly, research has tended to focus on recruitment rather than retention. In the USA, for example, researchers have looked at the problem of having insufficient trainees in subspecialties, including child and adolescent mental health ${ }^{12}$ and research. ${ }^{13}$ However, there has been some research into retention in New Zealand and Australia; this is likely because of the well-publicised shortages of psychiatrists there and the uneven distribution of psychiatrists in urban $v$. rural areas.

Two studies from Australasia investigating factors affecting retention identified some similar themes to us in terms of dissatisfaction. ${ }^{8,14}$ These included: the amount of contact with other physicians, ${ }^{8}$ the prestige of the specialty, ${ }^{8}$ the administrative role $^{8}$ and high stress levels from bureaucracy,. ${ }^{13}$ However, trainees also reported difficulties with supervision and professional support, ${ }^{8}$ which did not seem to be such an issue for UK trainees. Perhaps this is because in the UK we have benefitted from improvements following the Department of Health action plan. ${ }^{9}$

Another UK specialty which has experienced difficulties with training numbers is obstetrics and gynaecology. In 2003, the Royal College of Obstetricians and Gynaecologists (RCOG) set up a working party to look into recruitment and retention of trainees. When Deanery College Advisors were surveyed with regard to both recruitment and retention, few thought retention was a problem. ${ }^{15}$ Where it was, they attributed this to 'competing for experience (with midwives and registrars)', 'difficulty with the MRCOG Part 1 examination' and 'lack of further career opportunities'. Similar to the 2004 action plan, ${ }^{9}$ the RCOG report focused mainly on improving recruitment, for example by enhancing undergraduate experience, rather than looking in detail at retention of current trainees.

Despite possible improvements, there still remains significant ignorance and stigma outside of the psychiatric profession which appears to be affecting trainees. More needs to be done to raise the profile of our specialty and dispel some of the myths. Several interesting suggestions were made by trainees, such as involving psychiatrists in grand rounds in acute hospitals thus allowing us to present some of our challenging cases to colleagues. Better integration of psychiatry with the other specialties may increase understanding, as we are often separated geographically as well as philosophically.

\section{About the authors}

Christina Barras, Specialist Trainee in Psychiatry, Maudsley Hospital, South London and Maudsley NHS Foundation Trust, Jessica Harris, Core Trainee in Psychiatry, South West London and St George's Mental Health NHS Trust. 


\section{References}

1 Brockington IF, Mumford DB. Recruitment into psychiatry. Br J Psychiatry 2002; 180: 307-12

2 NHS Information Centre. NHS Vacancies Survey: England, 31 March 2010 NHS Information Centre, 2010.

3 Lambert TW, Turner G, Fazel S, Goldacre MJ. Reasons why some UK graduates who initially choose psychiatry do not pursue it as a longterm career. Psychol Med 2006; 36: 679-84.

4 Goldacre MJ, Turner G, Fazel S, Lambert T. Career choices for psychiatry: national surveys of graduates of 1974-2000 from UK medical schools. Br J Psychiatry 2005; 186: 158-64.

5 Cox J. Person-power. Reflections on the mental health National Service Framework for adults of working age. Psychiatr Bull 2000; 24: 201-2.

6 Storer D. Recruiting and retaining psychiatrists. Br J Psychiatry 2002; 180: $296-7$.

7 Wilson R, Corby CL, Atkins M, Marston G. Trainee views on active problems and issues in UK psychiatry. Collegiate Trainees' Committee survey of three UK training regions. Psychiatr Bull 2000; 24: 336-8.
8 Moloney J, MacDonald J. Psychiatric training in New Zealand. Aust NZ J Psychiatry 2000; 34: 146-53.

9 Royal College of Psychiatrists. Revised Action Plan on Recruitment and Retention of Psychiatrists. Royal College of Psychiatrists, 2004.

10 Postgraduate Medical Education and Training Board. National Training Surveys 2008-2009: Key Findings. General Medical Council, 2009.

11 Vize C. New Ways of Working for Psychiatry. New Ways of Working, 2009 (http://www.newwaysofworking.org.uk/content/view/59/470/).

12 Shaw JA, Lewis JE, Katyal S. Factors affecting recruitment into child and adolescent psychiatric training. Acad Psychiatry 2010; 34: 183-9.

13 Abrams MT, Patchan KM, Boat TF. Research Training in Psychiatry Residency: Strategies for Reform. National Academies Press, 2003.

14 Lau T, Shailesh K, Robinson E. New Zealand's psychiatrist work force: profile, recruitment and retention. Aust NZ J Psychiatry 2004; 38: $547-53$.

15 Royal College of Obstetricians and Gynaecologists. A Career in Obstetrics and Gynaecology - Recruitment and Retention in the Specialty. RCOG Press, 2006. 